\title{
How concrete removal techniques affect the bonding between concrete and repair mortar
}

\author{
Mohammad Ali Yazdi $^{1}$, Elien Dejager ${ }^{1}$, Mats Debraekeleer $^{2}$, Elke Gruyaert ${ }^{2}$, Kim Van Tittelboom ${ }^{1}$, Nele De Belie ${ }^{1}$ \\ ${ }^{1}$ Magnel Laboratory for Concrete Research, Department of Structural Engineering, Faculty of Engineering and Architecture, Ghent \\ University, Tech Lane Ghent Science Park, Campus A, Technologiepark Zwijnaarde 60, 9052 Ghent, Belgium \\ ${ }^{2}$ Technology Cluster Construction, Structural Mechanics and Building Materials, Department of Civil Engineering, KU Leuven, \\ Gebroeders De Smetstraat 1, 9000 Ghent, Belgium
}

\begin{abstract}
Many bonding failures between the substrate and repair mortar are attributed to too aggressive removal of the contaminated concrete and incorrect use of repair materials. To this end, in this study the effect of concrete removal techniques on substrates of different compositions and, as a result, on the bonding with repair mortar has been investigated. Substrate surfaces of different concrete compositions, micro-concrete (MC) and crushed stone concrete (CC), were treated by using three commonly used techniques: grit blasting (GB), jack-hammering (JH), and hydrodemolition/water-jetting (WJ). Automated Laser Measurements (ALM), sand patch tests and surface tensile strength measurements were applied to characterize the substrate surface. According to the results, the co-lateral effects of removal techniques such as WJ are dependent on the concrete mix composition. Moreover, WJ- and JH- treated samples achieved a lower surface tensile strength and bond strength compared to GB-treated slabs.
\end{abstract}

\section{Introduction}

Bond strength between concrete substrates and repair materials is influenced by parameters such as the saturation degree [1] and roughness [2] of the substrate surface, the applied removal technique [3], etc.

Based on the removal depth, concrete removal techniques are categorized into different classifications. For example, techniques such as grit blasting (GB) are used to remove or to clean the surface. Concrete removal techniques like jack hammering $(\mathrm{JH})$ or high-pressure water jetting (WJ) are usually used when a higher removal depth is the target [4]. However, these techniques, i.e. JH and WJ are usually referred to as "aggressive". The former is claimed to create microcracks in the superficial layer of the substrate, and as a result, to weaken the bond strength $[5,6,7]$. Research results on the latter sometimes contradict each other. Some research studies have reported the presence of microcracks caused by WJ $[6,8]$, while others did not $[9,10]$.

In this paper, GB, JH and WJ were applied and compared. The surface of the substrates were first characterized by Automated Laser Measurements (ALM), volumetric sand patch tests and surface tensile strength measurements. The bond strength between the treated substrates and the repair material was later quantified by performing pull-off tests.

\section{Materials and methods}

\subsection{Sample preparation}

Two concrete mixtures of micro-concrete (MC) and crushed stone concrete (CC) were prepared. For each mixture, 18 slabs with dimensions of $300 \mathrm{~mm} \times 300 \mathrm{~mm} \times$ $100 \mathrm{~mm}$ were made. Table 1 shows the mix composition of the concrete. The aggregate size is also shown in this table, with $\mathrm{CC}$ having the largest $\mathrm{D}_{\max }$. The effect of aggregate size on the contribution of removal techniques and the bond strength is later discussed. Superplasticizer was added to the system until the slump reached between 100 and $150 \mathrm{~mm}$.

Table 1. The concrete substrate mix design and characteristics.

\begin{tabular}{ccc}
\hline Materials & $\begin{array}{c}\text { Micro- } \\
\text { concrete } \\
\text { (MC) }\end{array}$ & $\begin{array}{c}\text { Crushed } \\
\text { stone } \\
\text { concrete } \\
\text { (CC) }\end{array}$ \\
\hline CEM I 52.5 N $\left(\mathrm{kg} / \mathrm{m}^{3}\right)$ & 470 & 340 \\
Water $\left(\mathrm{kg} / \mathrm{m}^{3}\right)$ & 188 & 153 \\
Sand $\left(\mathrm{kg} / \mathrm{m}^{3}\right)$ & 750 & 604 \\
Gravel 2/8 $\left(\mathrm{kg} / \mathrm{m}^{3}\right)$ & 946 & \\
Crushed limestone $2 / 6.3$ & & 336 \\
$\left(\mathrm{~kg} / \mathrm{m}^{3}\right)$ & & \\
Crushed limestone 6.3/20 & & 967 \\
$\left(\mathrm{~kg} / \mathrm{m}^{3}\right)$ & $\mathrm{x}$ & \\
Superplasticizer Glenium 27 & & $\mathrm{x}$ \\
Superplasticizer Viscocrete & & 0.45 \\
1020x & & 37.0 \\
W/C & 35.3 & \\
\hline
\end{tabular}


At the age of 3 months, the slabs were exposed to grit blasting (GB), jack hammering (JH) or water jetting (WJ) removal techniques: $\mathrm{GB}$ with a pressure of $0.7 \mathrm{MPa}, \mathrm{JH}$ using Air Hammer model 29062 with 3000 strokes per min and WJ with a high pressure of $130 \mathrm{MPa}$ were conducted. Afterwards, MasterEmaco S 5400 repair mortar was used to cover the surface of the treated substrates with a layer of $\pm 5 \mathrm{~mm}$ thickness to analyse the bond strength.

\subsection{Roughness}

\subsubsection{Automated Laser Measurement (ALM) method}

The roughness of the substrate surface was evaluated using Automated Laser Measurements (ALM). The height of the surface peaks and valleys $(\mathrm{Z})$ was measured with a high precision laser beam (sensor ILD 1800-50 and interface optoNCDT 1800, Micro-Epsilon Mess-technik $\mathrm{GmbH}$, Ortenburg, Germany; resolution $=5$ microns) mounted on an in-house developed measurement table equipped with two stepping motors that control the movement in the $\mathrm{X}$ and $\mathrm{Y}$ direction [11], see fig.1.

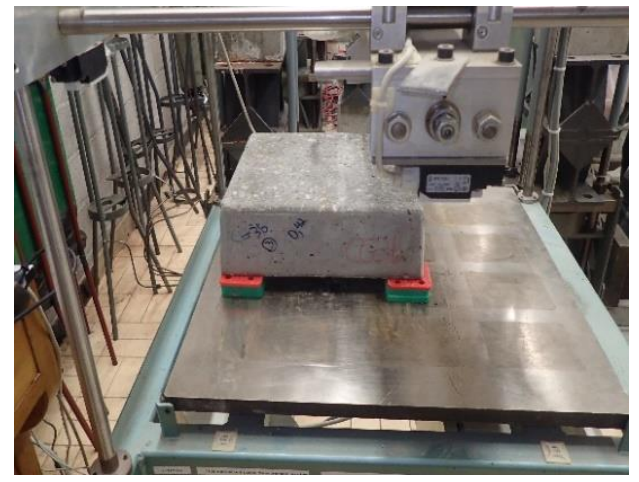

Fig 1. The ALM table.

For each concrete substrate, the surface profile was obtained in the $\mathrm{X}$-direction for 8 different $\mathrm{Y}$-positions, and vice versa, see fig. 2 . The traversing length was $250 \mathrm{~mm}$. Six samples per concrete composition and per pre-treatment technique were used for the ALM, however, for water-jetted slabs only one sample was used owing to the expense of the technique.

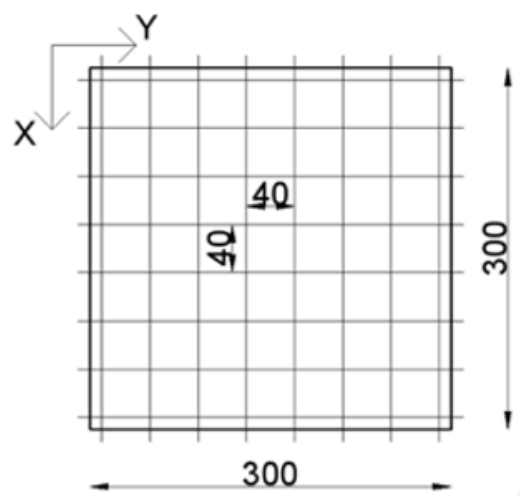

Fig 2. ALM direction.
In this study, the $R_{a}$ and the $R_{q}$ values were calculated according to the standard BS 1134 (2010) and were considered to evaluate the roughness of the substrate surfaces. The $R_{a}$ centre-line roughness value $(\mathrm{mm})$ is the arithmetic mean of the absolute ordinate values $Z_{i}$ within the sampling length. And, the $\mathrm{R}_{\mathrm{q}}$ root-mean-square roughness value $(\mathrm{mm})$ is the root mean square of the ordinate values $\mathrm{Z}_{\mathrm{i}}$ within the sampling length. Equations 2 and 3 mathematically express $R_{a}$ and $R_{q}$, respectively.

$$
\begin{gathered}
R_{a} \approx \frac{1}{n} \sum_{i=1}^{n}\left|Z_{i}\right| \\
R_{q} \approx \sqrt{\frac{1}{n} \sum_{i=1}^{n} Z_{i}^{2}}
\end{gathered}
$$

where $\mathrm{n}$ is the number of measurements, $\mathrm{Z}$ is the amplitude and $i$ is the measurement point number.

Fig. 3 shows an example of a roughness profile for a MC sample with and without taking the skew into account.

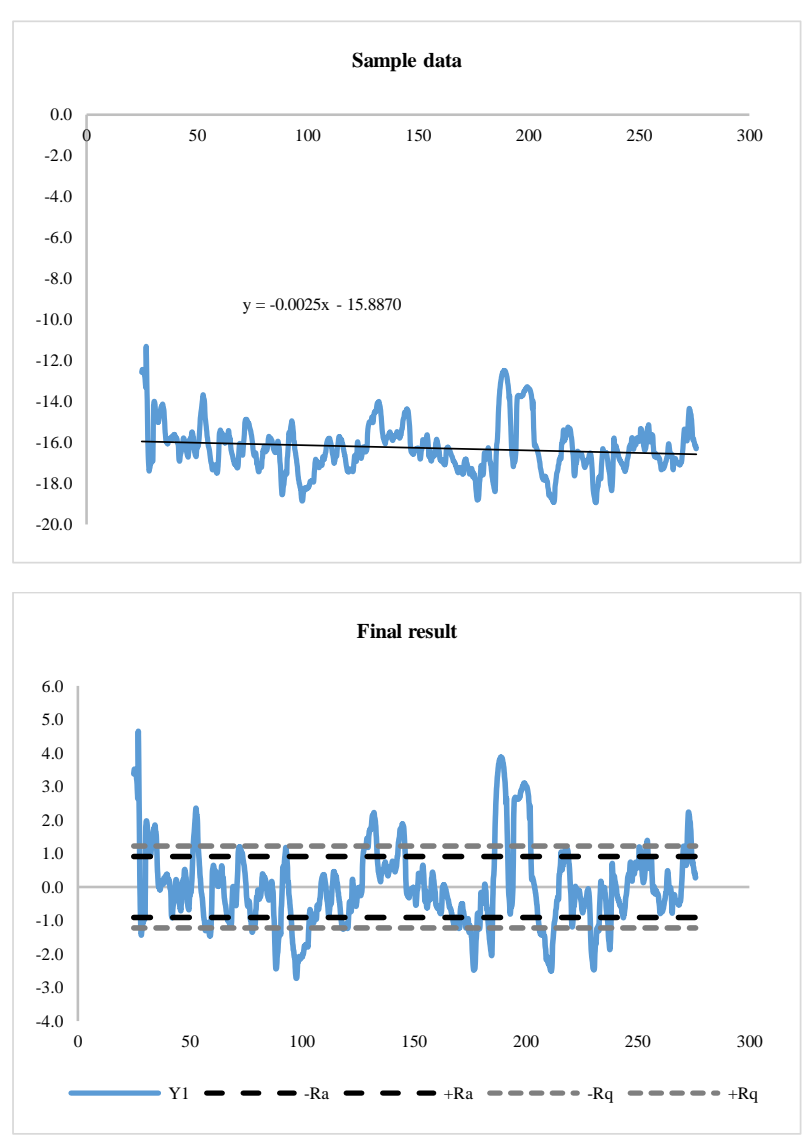

Fig 3. Roughness profile with (bottom) and without (top) skew adjustment.

\subsection{1 volumetric sand patch test}

The volumetric sand patch test method was performed according to EN 1766:2017. A heap was formed by placing $10 \mathrm{ml}$ dried silica sand with a grain size of 0.05 $\mathrm{mm}$ to $0.1 \mathrm{~mm}$ in the middle of the pre-treated surface of the substrates. Afterwards, a disk was used to uniformly spread the sand into a circular shape, see fig 4 . The diameter of the circle was measured three times (at angles of $0^{\circ}, 60^{\circ}, 120^{\circ}$ ) when no more sand could be moved. The 
roughness index $R_{i}(\mathrm{~mm})$ was finally calculated, as follows:

$$
R_{i}=\frac{4 V}{\pi d^{2}} 1000
$$

where $\mathrm{V}$ is the volume of sand used in the test $(\mathrm{ml})$ and $\mathrm{d}$ is the mean sand patch diameter $(\mathrm{mm})$.

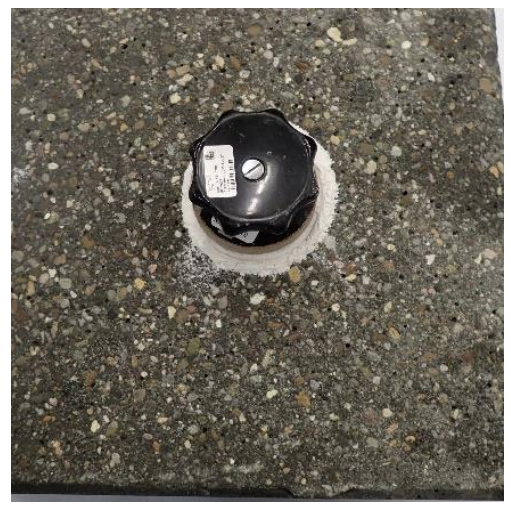

Fig 4. Sand patch test.

\subsection{Adhesion strength}

Three pull-off tests were performed according to NBN EN 1542 on each substrate before and after the repair mortar was applied. The former was to measure the surface tensile strength, and the latter was performed 28-days after the repair mortar was applied in order to evaluate the bond strength between the substrate and the repair material. In order to perform the test, three cores with a diameter of $50 \mathrm{~mm}$ were drilled $15 \mathrm{~mm}$ deep into the substrate surface, and then a dolly was glued to each core using epoxy resin. After $24 \mathrm{~h}$ the pull-off test was conducted using the Proceq DY-2 device shown in fig. 5. Both strengths were finally calculated using the following equation (4):

$$
f_{h s}=\frac{4 F_{h}}{\pi D^{2}}
$$

where $f_{\mathrm{hs}}$ is the final strength $\left(\mathrm{N} / \mathrm{mm}^{2}\right), \mathrm{F}_{\mathrm{h}}$ the failure load $(\mathrm{N})$ and $\mathrm{D}$ the mean diameter $(\mathrm{mm})$.

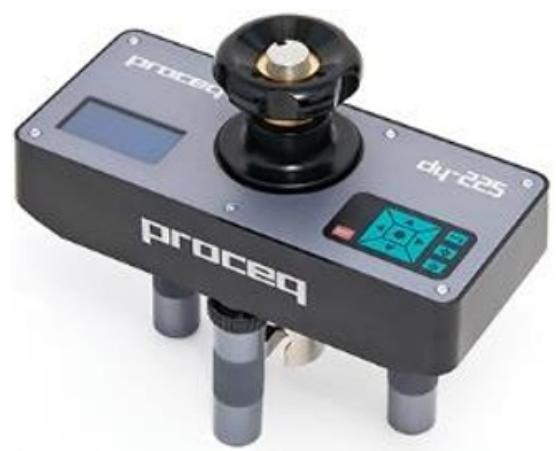

Fig 5. The pull-off device.

\section{Results and discussion}

\subsection{Roughness}

Fig. 6. shows the ALM results of GB-, WJ- and JH-treated substrates. According to BS 1134:2010, for machining processes that produce lays, the maximum value achieved from the results of measurements in different directions would be considered as a roughness parameter. Therefore, in this study, the value given in fig. 6 for WJ-treated samples, is the highest roughness obtained in either $\mathrm{X}$ or Y. However, for other pre-treated samples the average of $\mathrm{X}$ and $\mathrm{Y}$ direction is plotted in fig.6.
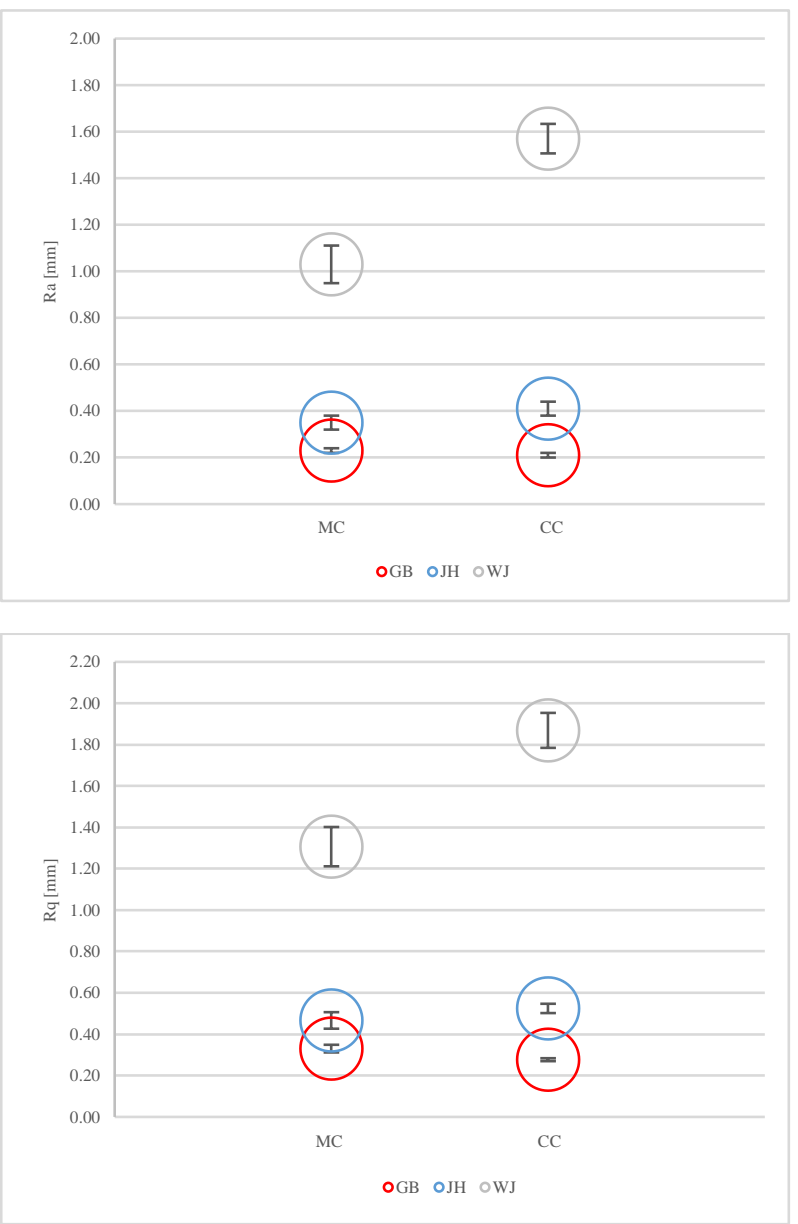

Fig 6. Degree of roughness, $R_{a}($ top $)$ and $R_{q}$ (bottom). Error bars represent the standard error.

As can be observed from fig.6, WJ results in a much rougher surface compared to $\mathrm{GB}$ and $\mathrm{JH}$. When concrete compositions are compared, it is observed that the roughness is higher in $\mathrm{WJ}$-treated $\mathrm{CC}$ mixtures compared to MC mixtures, showing the dependence of $\mathrm{WJ}$ on the concrete composition. The observation of a higher degree of roughness in CC compared to MC might be because of the difference in aggregate size of these mixtures. In fact, $\mathrm{CC}$ has larger aggregates than MC (see table 1). However, the contribution of other techniques such as GB and $\mathrm{JH}$ are shown not to be dependent on the mix composition.

Fig. 7 shows the sand patch test results of MC and CC mixtures. As can be seen in the figure, the degree of roughness was the highest for WJ-treated $\mathrm{MC}$ and $\mathrm{CC}$ 
mixtures compared to the other treated substrates. This finding corresponds with the outcome of the ALM. However, the mix composition effect on the roughness of the substrates is not expressed in the sand patch test results, showing that this test method might not be precise enough. This was also reported in [12]. With regard to GB- and JH-treated samples, a good overlap can be seen on the results achieved by the sand patch test, regardless of the mix composition.

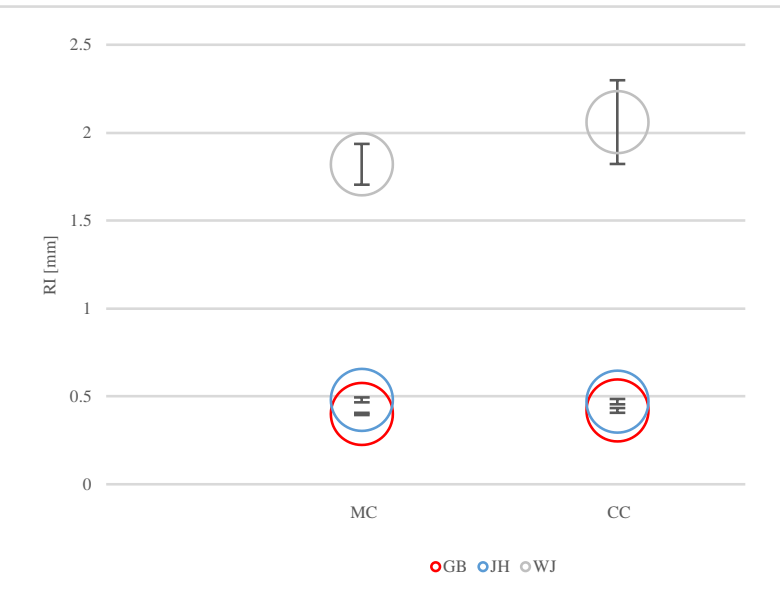

Fig 7. Sand patch test results. Error bars represent the standard error.

The Belgian Construction Certification Association has defined three main texture classifications, as specified within PTV-BB-563 (2007), depending on the roughness of the substrate surface, see Table 2.

Table 2. The texture classification of substrate surface.

\begin{tabular}{cc}
\hline Texture & Roughness index \\
\hline Smooth & less than $0.2 \mathrm{~mm}$ \\
Sandblasted & Between 0.2 and $0.5 \mathrm{~mm}$ \\
Rough & Greater than $0.5 \mathrm{~mm}$ \\
\hline
\end{tabular}

Both ALM and sand patch test results show that GB- and JH- treated surfaces are placed in "sandblasted" classification. However, WJ-treated samples with roughness index of over $0.5 \mathrm{~mm}$ is classified as "rough", according to table 2 .

\subsection{Adhesion strength}

The surface tensile strength and bond strength of pretreated samples are shown in fig. 8. As can be seen, GB, regardless of the mix composition, achieved the highest surface tensile strength, followed by JH and WJ. The bond strength results shown in fig. 8 follow the same trend as that of the surface tensile strength, except for WJ-treated MC samples, where a higher bond strength is seen compared to that of JH-treated MC slabs. In general, GBtreated samples have the highest bond strength and surface tensile strength compared to $\mathrm{JH}$ - and WJ-treated slabs. This could be because of the difference in the degree of roughness of these pre-treated mixtures.
Moreover, the fact that the latter techniques, i.e. JH and $\mathrm{WJ}$ are much more aggressive than GB and thus belong to a different classification should not be forgotten. GB is mainly used for cleaning or removing the substrate surface, but $\mathrm{JH}$ and $\mathrm{WJ}$ techniques have the potential to remove the cover or even matrix concrete, depending on the removal energy. Therefore, the potential detrimental effects caused by $\mathrm{JH}$ and $\mathrm{WJ}$ on the concrete substrates, and as a result, on the strength, can be more pronounced.

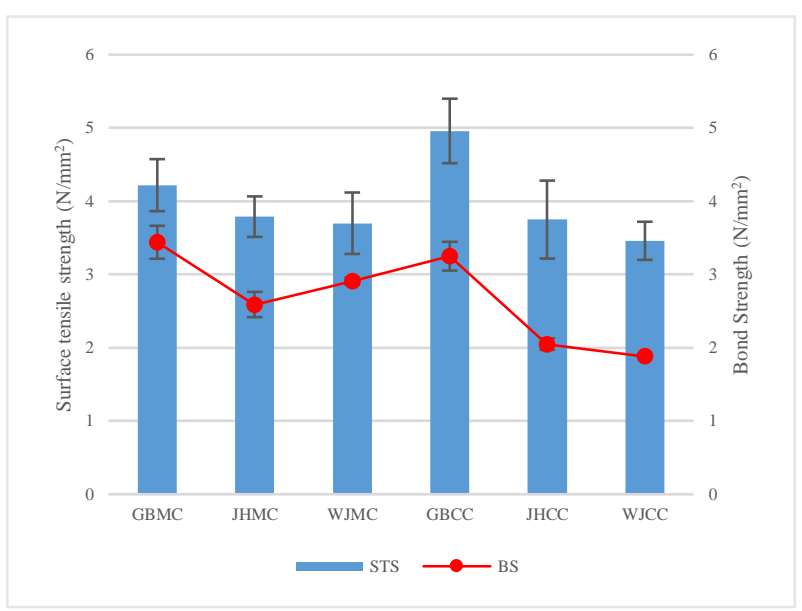

Fig 8. Surface tensile strength and bond strength results (STS: surface tensile strength and BS: bond strength). Error bars represent the standard error.

The presence of microcracks has been reported as one of the main reasons causing the reduction in bond strength of samples treated by $\mathrm{JH}[5,6,7]$. Some microcracks caused by $\mathrm{JH}$ were also observed in this study, see fig.9.

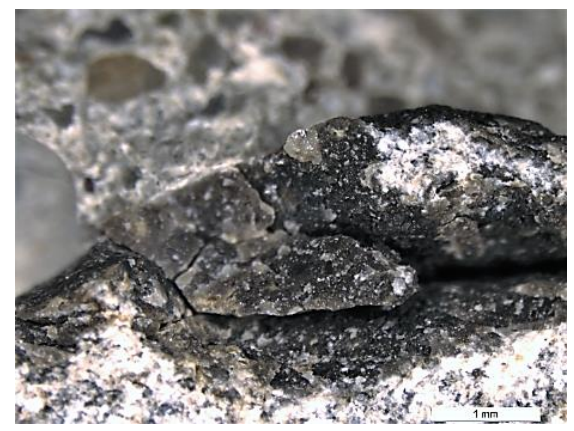

Fig 9. An example of detected cracks caused by JH.

Fig. 10 shows an example of surface tensile strength failures in the concrete substrates of $\mathrm{JH}$-treated $\mathrm{CC}$ and MC samples. Failures in the superficial layer of jack hammered substrates (see fig.10) have been widely reported in literature $[6,13]$ and been attributed to the presence of microcracks at this layer.

As can be seen, failures were predominantly dependent on the mix composition. For example, for JH-treated MC samples almost no failures take place in the superficial layer, while for JH-treated CC samples 2 out of 3 failures are in a zone very close to the surface. Moreover, some irregularities were observed in the failures of CC samples 
(shown in fig.10), which can be because of the aggregate size and shape in these mixtures.
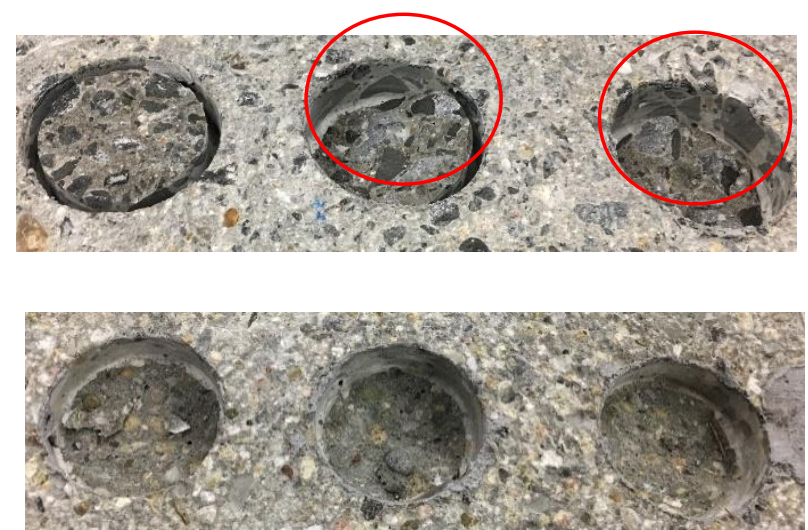

Fig 10. Surface tensile strength failures in the substrates of jack hammered CC (top) and MC (bottom).

\section{Conclusion}

The results of this study show a much higher degree of roughness in WJ-treated samples compared to GB- and JH-treated slabs. This was seen in both the ALM and the sand patch test results. However, the sand patch test method seems not to be a proper method for roughness measurement of substrates with a very rough surface. On the contrary, the ALM method gave more reasonable results when the roughness of different mix compositions (MC and CC) was compared.

WJ was shown to influence the mixtures based on their compositional features such as aggregate size. Both JH and $\mathrm{WJ}$ achieved a lower bond strength as well as surface tensile strength compared to GB. The reduction in $\mathrm{JH}-$ treated samples could be due to the microcracks created during the hammering process. However, the fact that GB belongs to a different classification, and therefore, possesses different applications and removal energy compared to $\mathrm{JH}$ and $\mathrm{WJ}$ should be taken into account for future research studies in this field.

\section{References}

1. L. Courard, B. Bissonnette, A. Garbacz, A.M. Vaysburd, and K.F. von Fay, Guidelines for concrete surface preparation: 10 years research and experience. in MATEC Web of Conferences. EDP Sciences, 2018.

2. F. Perez, M. Morency, B. Bissonnette, and L. Courard, Correlation between the roughness of the substrate surface and the debonding risk. in 2nd International Conference on Concrete Repair, Rehabilitation and Retrofitting, ICCRRR-2. Cape Town, South Africa: CRC Press, 2008.

3. S. Matthews, CONREPNET: Performance-based approach to the remediation of reinforced concrete structures: Achieving durable repaired concrete structures. J. Build. Apprais., 2007. 3(1): p. 6-20.

4. M.C. Vorster, J.P. Merrigan, R.W. Lewis, and R.E. Weyers, Techniques for concrete removal and bar cleaning on bridge rehabilitation projects. National Academy of Sciences, Washington, DC, 1992.

5. J. Silfwerbrand and H. Beushausen, Bonded concrete overlays-bond strength issues. in Proceedings ICCRRR 2005 International Conference on Concrete Repair, Rehabilitation and Retrofitting, Cape Town, South Africa, Taylor \& Francis Group, London. 2006.

6. L. Courard, T. Piotrowski, and A. Garbacz, Near-tosurface properties affecting bond strength in concrete repair. Cem. Concr. Comp., 2014. 46: p. 73-80.

7. C. Talbot, M. Pigeon, D. Beaupré, and D. Morgan, Influence of surface preparation on long-term bonding of shotcrete. Mater. J., 1995. 91(6): p. 560566.

8. L. Courard, B. Bissonnette, and N. Belair, Effect of surface preparation techniques on the cohesion of superficial concrete: comparison of jack-hammering and water jetting. in Concrete Repair, Rehabilitation and Retrofitting. Cape Town, South Africa: Taylor \& Francis Group, 2006.

9. A. Garbacz, L. Courard, and B. Bissonnette, A surface engineering approach applicable to concrete repair engineering. Bulletin of the Polish Academy of Sciences: Technical Sciences, 2013. 61(1): p. 73-84.

10. B. Bissonnette, L. Courard, H. Beushausen, D. Fowler, M. Trevino, and A. Vaysburd, Recommendations for the repair, the lining or the strengthening of concrete slabs or pavements with bonded cement-based material overlays. Mater. Struct., 2013. 46(3): p. 481-494.

11. N. De Belie, J. Monteny, A. Beeldens, E. Vincke, D. Van Gemert, and W. Verstraete, Experimental research and prediction of the effect of chemical and biogenic sulfuric acid on different types of commercially produced concrete sewer pipes. Cement and Concrete Research, 2004. 34(12): p. 2223-2236.

12. P.M.D. Santos and E.N.B.S. Julio, comparison of methods for texture assessment of concrete surface. ACI Mater. J., 2010. 107(5): p.433-440.

13. A. Garbacz, M. Górka, and L. Courard, Effect of concrete surface treatment on adhesion in repair systems. Mag. Concrete. Res., 2005. 57(1): p. 49-60. 